\title{
Poverty Eradication Inspired Computing
}

\author{
Monday Eze \\ Dept. of Computer Science \\ Federal University, Ndufu-Alike, Ikwo, Ebonyi State, Nigeria
}

\begin{abstract}
This work is a foundational research, aimed at drawing the attention of computer scientists to poverty eradication as a serious global concern. It provides requisite system conceptualizations for more vigorous actions against poverty through the application of computing. In it, the researcher attempts to build a framework for the emergence of a new computing frontier tagged "Poverty Eradication Inspired Computing". Quite a number of complex human problems have been solved in the past through the application of Computer Science and Information Technology. An increased focus of computing towards poverty eradication is therefore expected to yield more impressive results. Poverty Eradication Inspired Computing as proposed in this work refers to computing efforts borne out of a strong desire to eradicate poverty. It is an emerging field which stresses the use of computing as a tool for anti-poverty drive. This research introduces the Hexagonal Model, and uses it to outline the core functional domains for the application of Poverty Eradication Inspired Computing. Corruption Eradication Inspired Computing, National Poverty Discovery Database, Agric Inspired Computing and a number of other related new system concepts are all explained in this research. Since the issue under study is an open and evolving one, this work makes some recommendations as well as calls for inputs from other researchers who share similar concerns. The overall objective is to fully eradicate poverty through the application of Computer Science and Information Technology.
\end{abstract}

\section{General Terms}

Scientific Computing, Computer Applications.

\section{Keywords}

PERI Computing, Foundational Research, Computational Framework, Poverty Eradication Inspired Computing.

\section{INTRODUCTION}

The Macmillan Dictionary Online [1] defined poverty as apparent lack of the means to pay for one's basic needs. The World Bank described it as the experience of living below a minimum level of income, such as a dollar a day per person [2]. It further explained that poverty is the lack of adequate food, shelter, health, education, and influence over decisions that affect one's life. According to the Encyclopedia Britannica [3], poverty is the state of human life, closely associated with poor health, low levels of education or skills, unemployment, and high rates of disruptive behavior. The eradication of poverty calls for a more dedicated computational solution. For instance, in a recent United Nations Conference on Trade and Development, it was stated that the Least Developed Countries' share of the global population living in extreme poverty has doubled since 1990 [4]. Furthermore, it is estimated that close to half the world population live in abject poverty [5]. At the moment, poverty is tagged the biggest challenge to world development, such that about $50 \%$ of the world lives on an income of less than $\$ 2$ per day [6]. These and many other reasons underline the necessity for the global community to focus more computing efforts towards poverty eradication. This research proposes the emergence of Poverty Eradication Inspired Computing (PERI Computing) as an evolving field which focuses on the use of computing for poverty eradication.

\section{HEXAGONAL MODEL}

This work proposes the use of Hexagonal Model for PERI Computing. As the name suggests, it is a structural diagram consisting of six component parts, each identifying the six key areas for the application of computing in the poverty eradication drive. Based on an in-depth survey on global poverty prevalence, it is evident that these six focal areas cannot be ignored if the fight against poverty is to be realistic. The diagrammatic model as shown in Fig. 1F thus outlines the key areas for the initial focus of PERI Computing. Since the issue under study is an open one, it follows that the hexagonal model is by no means exhaustive. As outlined in the figure, the frontiers proposed for PERI Computing are Mass Literacy Inspired Computing (MLIC), Job Creation Inspired Computing (JCIC), Disease Eradication Inspired Computing (DEIC), Anti-Corruption Inspired Computing (ACIC), Rural ICT (RICT), and Agric Inspired Computing (AGIC).

\subsection{Mass Literacy Inspired Computing}

One of the major impediments to human development is illiteracy [7]. The Millennium Development Goal (MDG) reiterated the need to quickly tackle the menace of poverty through widespread literacy [8]. Illiteracy is strongly linked to poverty. Thus, a recent research suggests that every poverty reduction strategy should include steps to develop basic adult literacy [9]. A canonical correlation research on the relationship between poverty and illiteracy reported a statistical significance between the two [10]. In that work, the authors further concluded that literacy significantly reduces the likelihood of household poverty. It therefore follows that there is an urgent need to harness the available computing resources and techniques to deal with illiteracy. By dealing with illiteracy through computing, it is obvious that one is indirectly tackling poverty at the grassroots.

\subsection{Job Creation Inspired Computing}

A number of researches have pointed out that unemployment is one of the root causes of poverty [11]. One of the key areas 


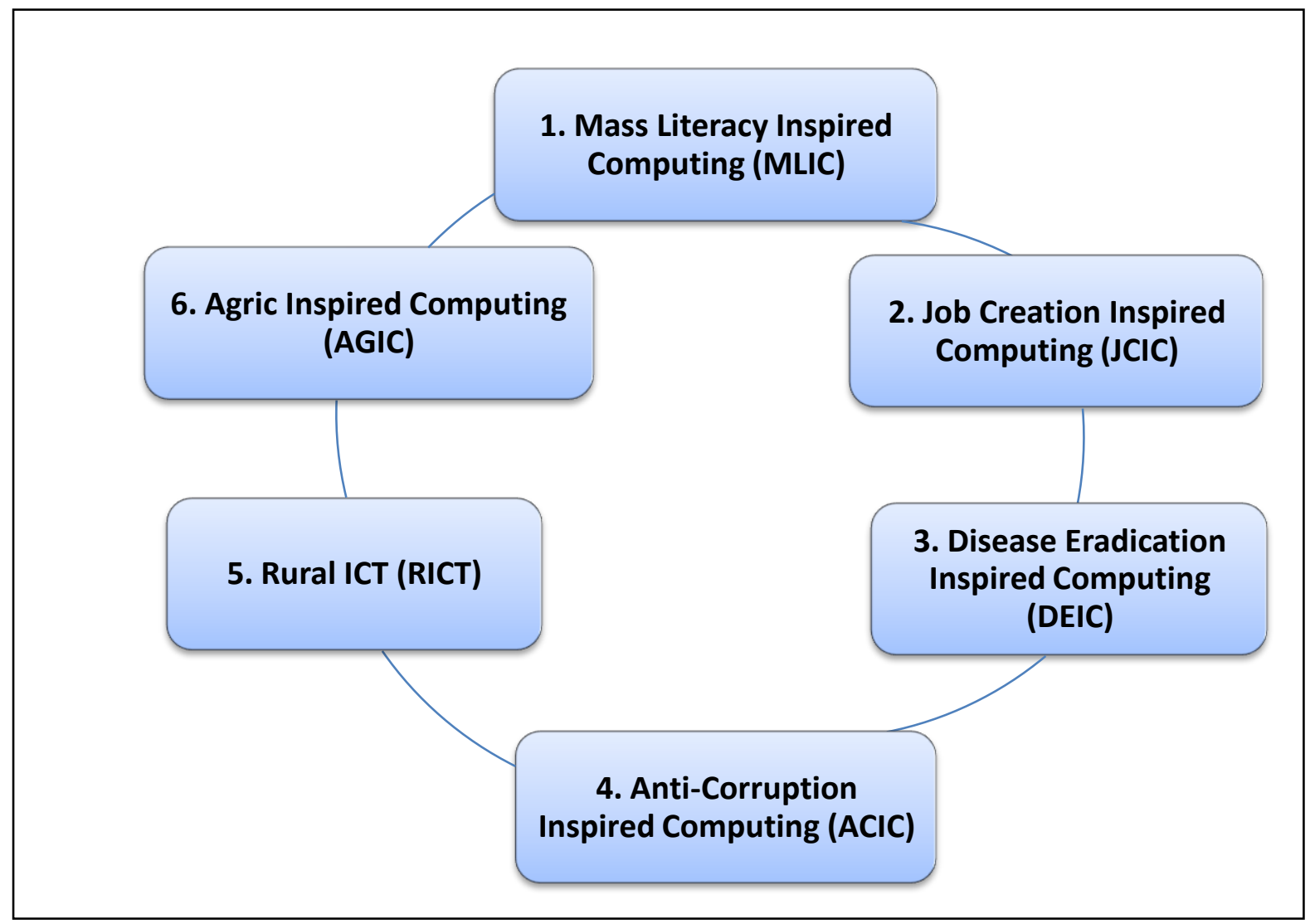

Fig. 1F: The Hexagonal Enumeration Model

that should be tackled through PERI Computing is the issue of job creation. Unemployment leads to the ripple effects of poverty, and has also been identified as one of the sources of global insecurity [12]. The necessity for an increased focus of computing to deal with unemployment has been underlined by a number of researches. For instance, [13] asserts that unemployment is getting more acute in many countries than it was about two decade ago. One of the core agenda for PERI Computing should therefore be the evolution and implementation of computer-driven strategies for tackling unemployment at all levels. By dealing with unemployment through computing, it is obvious that one is also indirectly tackling poverty at the grassroots.

\subsection{Disease Eradication Inspired Computing}

At the very root of poverty is the plague of diseases [14]. Obviously, there is a need to intensify the use of computing resources to stem the spread of diseases. Computer Scientists should put more efforts in studying the transmission of infectious diseases, and applying the resulting knowledge to build requisite computational models. Fig. $2 \mathrm{~F}$ is the Disease Eradication Inspired Computing (DEIC) Pyramid showing the suggested computational strategies for implementing disease eradication through computing. As shown in the DEIC Pyramid, the establishment of IT-driven Disease Eradication Research Institutes is one of the core strategies for driving disease eradication through computing. This underscores why this activity is positioned at the base of the pyramid. Examples of existing institutions in this regard are the Institute for Computational Medicine, Johns Hopkins
University [15], the Institute for Disease Modeling, Bellevue [16], and the Center for Disease Modeling, York University, Canada [17], among others. The next strategy in the pyramid is an increased focus on disease transmission environmental modeling. Epidemiologists have established the fact that for disease transmission to take place there must be a tripartite interaction of three components. These components make up what [18] called the epidemiological triangle - the disease agents, the host, and the environment. According to [19], the disruption of the triangular equilibrium usually disrupts a disease outbreak. Computer Scientists should therefore focus their modeling activities not only on the disease agents and hosts, but also on the transmission environment. The next issue in the pyramid is the flexibility of university computer science curricula to disease eradication studies. The application of computing to disease eradication should be included in the computer science undergraduate and postgraduate curricula of universities. A right step in this direction is the widespread introduction of Bioinformatics to the Computer Science curricula of many universities. Bioinformatics is a practical application of scientific computing to study biological processes [20]. Sharing of disease eradication inspired computing information is another issue of utmost importance in the DEIC Pyramid. The need for mutual information sharing and collaboration by computer scientists in the area of disease eradication research cannot be overemphasized. By attempting to eradicate diseases through computing, it is obvious that one is also indirectly tackling poverty at the grassroots. 


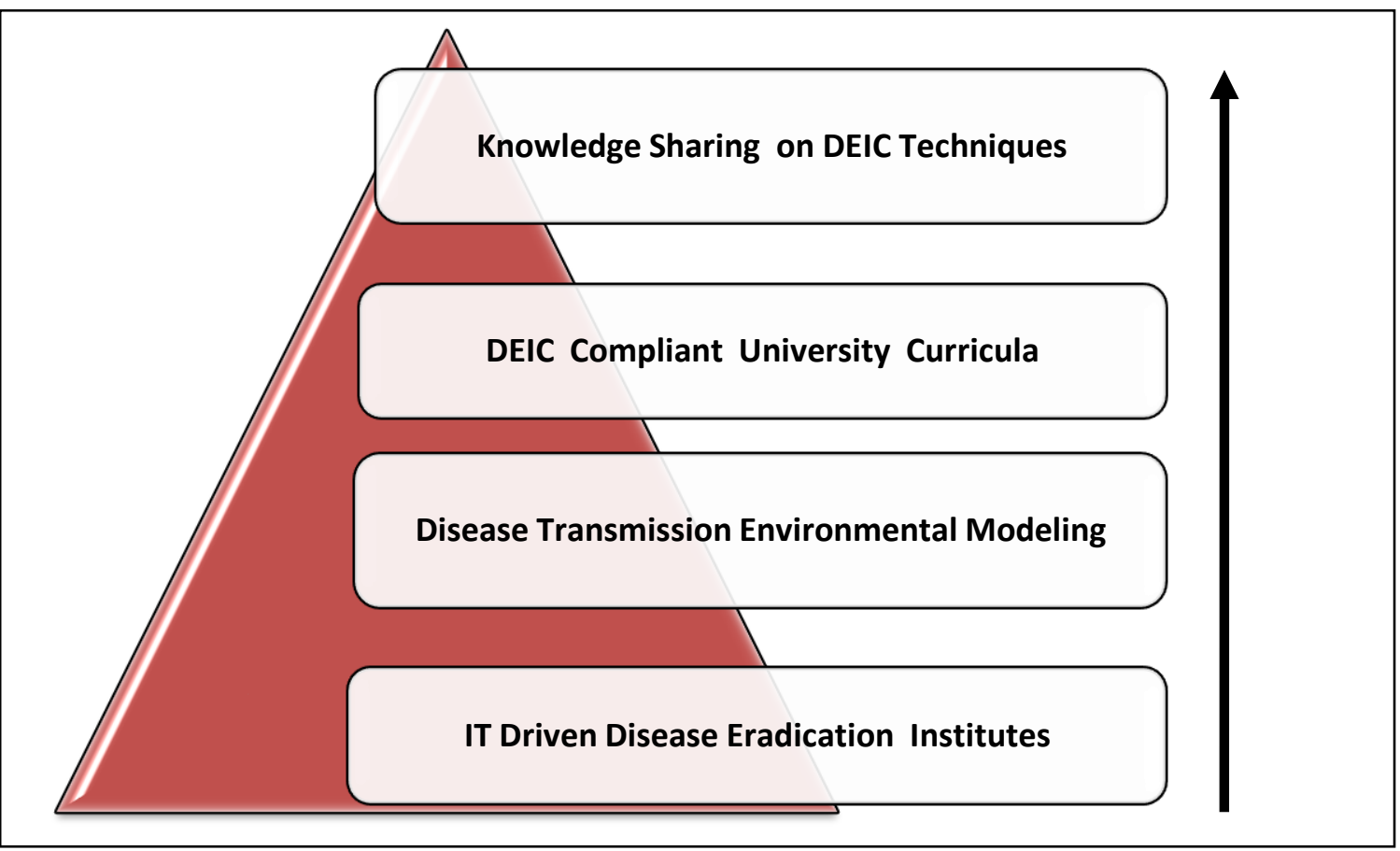

Fig. 2F: The DEIC Pyramid

\subsection{Anti-Corruption Inspired Computing}

Corruption has been described as one of the major reasons for poverty in developing countries [21]. For instance, the Corruption Index measure by the Transparency International shows that the most corrupt countries of the world are within the bracket of the poorest group [22]. Proponents of anticorruption in governance have proposed the use of eGovernance as a panacea to the problem of corruption [23]. One of the success stories in this regard was demonstrated in the case study on the positive impacts of e-Governance in Kuwait [24]. However, while e-governance could help fight corruption, [25] has stressed that its effective implementation demands sound ICT infrastructure. It is for this reason that the potential of e-Governance has remained grossly unexploited in many developing economies [26]. A number of governments have taken to computing in order to deal with the menace of corruption [27]. This is termed in this research as Anti-corruption Inspired Computing (ACIC). The expected resultant effect is an equitable distribution of the national wealth, and invariably, the eradication of poverty. For instance, using requisite computing technology, the Kenya Anti-Corruption Commission reportedly identified some generic loopholes in the public institutions [28]. In a similar way, it has been mentioned [29] that Information Technology is at the center point of the Namibia Governments Vision 2030. Thus, the road map envisions the full utilization of eapplications across all works of life, such as e-Health, eEducation, e-Mining, e-Transport, e-Agriculture, etc. Another effort that aligns with the concept of anti-corruption computing is the European Anti-Corruption Centre (EurACC) envisioned as a full-fledged world class anti-corruption entity. The EurACC is said to have one of the largest anti-corruption search engine and database retrieval systems in the world [30]. It is necessary for more computing efforts to be devoted to anti-corruption system developments. This is because a war against corruption is invariably a war against poverty

\subsection{Rural ICT}

Information and Communication Technology could be used to fight against poverty in the rural areas. A research by [31] studied the impact of telecenters set up by a joint project between the United Nations Development Program (UNDP) and the Chinese Government in the rural villages in Wu'an, China. The author outlined the numerous transformative roles of the telecenters on the rural poor. Some of the listed benefits are, rural economic boom, e-literacy, driving of new farming techniques, community social integration, knowledge sharing, among others. Microsoft has also delved into rural computing projects. One of such initiatives is the Saksham which was recently launched in India to energize the rural economy by creating an environment for meaningful development [32]

\subsection{Agric Inspired Computing}

Time is ripe for computer scientists to invest their ingenuity in building IT enabled agricultural sectors. This is what [33] described as 'Informised Agriculture'. An increased focus on productive agriculture could reduce the prevalence of hunger, and invariably poverty. The full exploration, development and harnessing of computing to improve the agricultural sector is the aim of Agric Inspired Computing. Though the term is relatively new, the concept itself is quickly gaining grounds. For instance, a team of Japanese computer scientists [34] recently delved into the application of sensors technology, wireless networks, and cloud computing in Agriculture. The researchers explained that the resulting models which have already been tested in two Japanese farming corporations would be formalized for broader applications. Similarly, the Malaysian Government has also applied Radio-Frequency Identification (RFID) in livestock farming. The RFID is a wireless technology that uses electromagnetism for automatic identification and tracking of moving objects. The technology stores information in electronic tags which can be recognized by a special reader. Unlike a barcode which must be within the line of sight of the reader, RFID could be embedded in the tracked object such as the livestock. Another area of 
computing that is quickly taking root in productive agriculture is mobile computing. Thus a research by [35] pointed out that agriculture is fast becoming an information intensive enterprise. Mobile Agriculture is reported to be already imbibed by over $40 \%$ of the farmers in the North America and Europe [35]. This is possible because of the widespread ownership of smart phones, tablets, among others. Again, while soft computing techniques have been extensively applied in engineering and biological sciences, they are also quickly becoming very relevant to the field of agricultural sciences [36]. Soft computing is defined as the use of inexact computing techniques to solve complex real life problems. A complex problem in this regards is defined as one without other known cost-effective conventional solution paths. Soft computing methods include fuzzy logic, genetic algorithms, artificial neural networks, decision trees, support vector machines, and so on. Soft computing has been used to study the effects of soil and water to crop growth, as well as for analyzing food processing operations.

\section{CORE ATTRIBUTES OF PERI COMPUTING}

It is necessary to pinpoint some parameters for distinguishing PERI Computing efforts from other forms of Information Technology activities. The three core attributes identified to qualify a computing effort as poverty eradication inspired are depicted in the block diagram in Fig. 3F. Thus, PERI Computing efforts should be humanitarian driven. It should take the nature of computing for fun. Furthermore, it should also be inventive.

\subsection{Humanitarian-Driven Computing}

Most Computing efforts are profit driven. PERI Computing is however a slight deviation from this norm, since it is expected to be non-profit in nature. Humanitarian Driven Computing is the root of PERI Computing. Here, the computer scientists look beyond immediate financial gain and rather embrace humanitarian sacrifices in order to alleviate the suffering of others, especially the poor in the society.

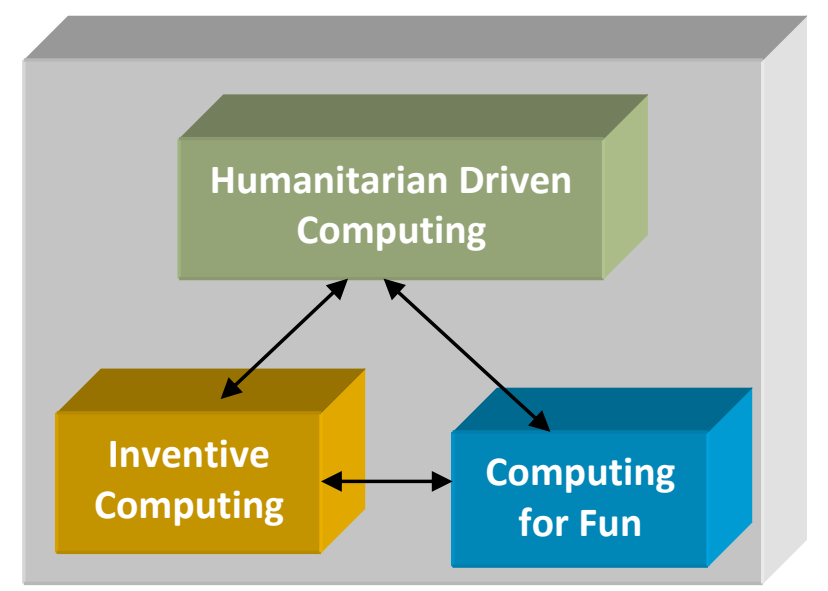

Fig. 3F: Three Attributes of PERI Computing

\subsection{Computing for Fun}

Another core attribute required of poverty eradication inspired scientific work is fun. In other words PERI Computing demands working with unlimited passion in the application of computer-driven knowledge to eradicate poverty.

\subsection{Inventive Computing}

Here, the field of computing is viewed as a platform for inventions. Just like inventors in other fields of human endeavoures, a computational inventor is poised to evolve new techniques and technologies that would benefit future generations. PERI Computing encourages inventive computing.

\section{CONCLUSION}

It has been argued that technology is of no importance if it does not impact the lives of human beings. The above assertion appears to be the case in computing. The relevance of Computing and Information Technology will definitely be felt more when it is fully harnessed to solve human related problems. One of such widespread human problems is that of poverty. Computing efforts should therefore be fully deployed to eradicate poverty worldwide. It is in line with this objective that this research has proposed the adoption of PERI Computing as a strategy for poverty eradication. One of the outputs of this research is the Global Extreme Poverty (GEP) Graph shown in Fig. 4F. The GEP Graph is plotted from the dataset obtained from the latest World Bank / IMF Joint Report on Global Poverty [37]. A range of years beginning from 1990 are plotted on the $\mathrm{x}$-axis against the percentage poverty for selected regions on the y-axis. The five regions of the world covered by this plot are the East Asia, Latin America, Middle East, South Asia and Sub-Saharan Africa. The graph for each region is clearly shown using a designated colour code.

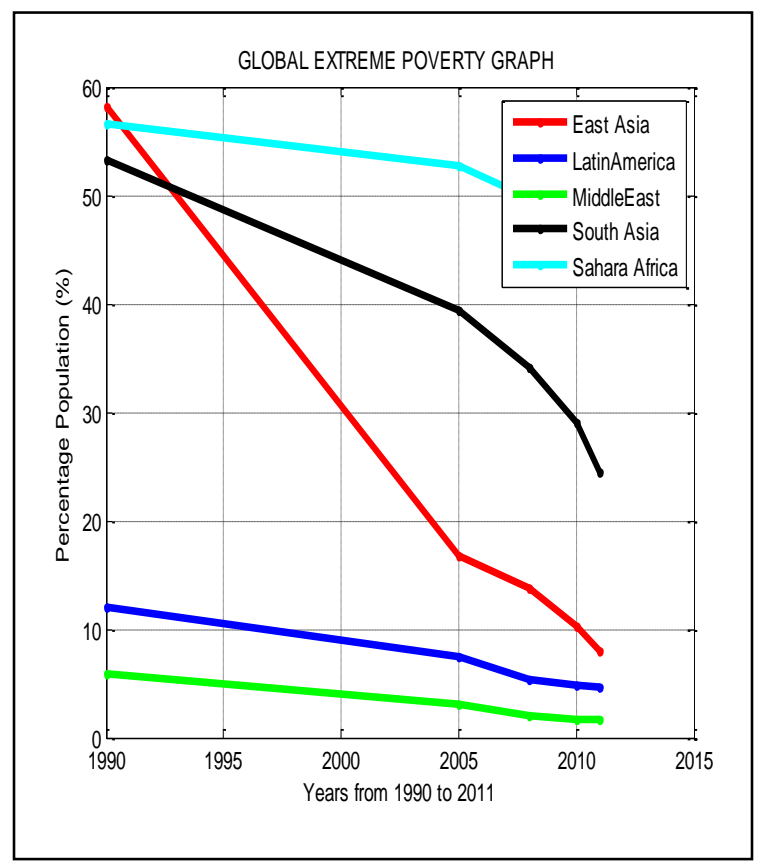

Fig. 4F: Global Extreme Poverty Graph

As can be deduced from the GEP Graph, a high percentage of the world population is still under the grip of extreme poverty. The term extreme poverty is defined as a category of poverty where someone lives below an income of $\$ 1.25$ per day [37]. In conclusion, the need for urgent computational intervention against poverty cannot be overemphasized. This is the main essence of this research. 


\section{FUTURE RESEARCH}

One of the projects proposed for future works is the implementation of National Poverty Discovery Database (NPDD). The aim of the project is to ensure that accurate poverty related data are successfully mined in a timely manner for use in the fight against poverty. Such a data resource is expected to be of immense benefit to policy makers, governments, non-governmental organizations and computer scientists. The framework for the database is shown in Fig. 5F.

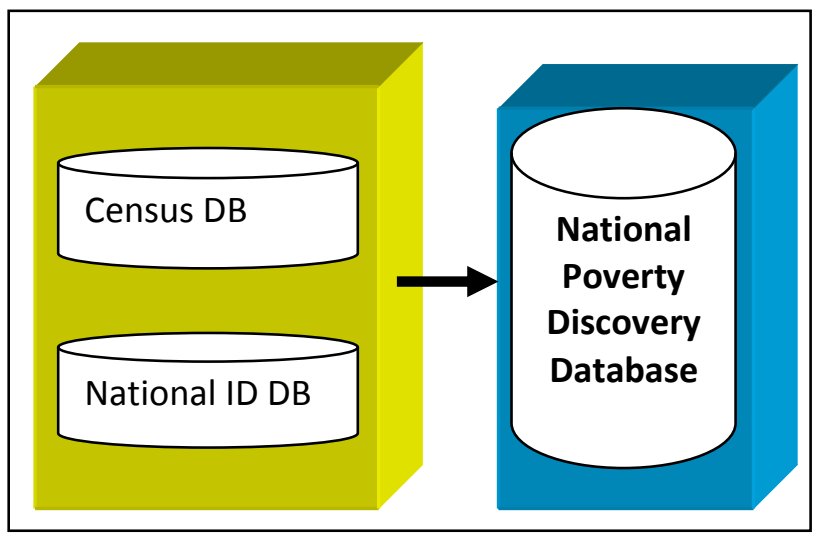

Fig. 5F: National Poverty Discovery Database Framework

Without having adequate information on who are the poor, where are they located, what is the percentage of the poor in the society, and why are they poor, the efforts to eradicate poverty may be impeded. A dedicated database that houses such poverty-related information could be very essential. As shown in the workflow diagram in Fig. 5F, one way to build the proposed NPDD is to extract the relevant information directly from the existing national databases such as Census Database, National ID Database, and so on. Another future project is to launch a massive IT-driven orientation on PERIComputing. The aim of that is to solicit the support of other computer scientists in the poverty eradication drive.

\section{REFERENCES}

[1] Macmillan. 2014. Poverty (Accessed online on Dec 1, 2014). http://www.macmillandictionary.com

[2] World Bank Group. 2014. The Challenge: Reducing Poverty. (Accessed online on Dec 1, 2014), www.worldbank.org/progress/reducing_poverty.html

[3] Encyclopedia Britannica, 2014. Poverty. (Accessed online on Dec 1, 2014 in the following website). www.britannica.com/EBchecked/topic/473136/poverty

[4] UN. 2011. Poverty Reduction and Progress towards MDGs in the LDCs: Encouraging Signs but Much Remains to be Done, UN Conference on Trades \& Development: The Least Developed Countries (LDC) Series, May 2011,

[5] Chilosi, A. 2010. Poverty, Population, Inequality, and Development: the Historical Perspective, The European J. of Comparative Econs, Vol. 7 (2), pp. 469-501

[6] Kiran, S. 2012. Changing Profile of Urban Poverty A Case Study of Jharkhand (India), Transcience, Vol. 3 (2), pp 37-50.
[7] Babatola, A. and Olufunke, M. 2012. Towards Achieving Functional Adult Literacy in Nigeria. European Scientific Journal, Vol. 8 (5), pp209-218

[8] Elaine, U. 2013. Education for All, the MDGs, and human development: Working Paper Series, Institute of Education, University of London.

[9] Carew, T. 2002. Improving livelihoods for the poor: the role of literacy, DFID Background Briefing, Department for International Development, London

[10] Ogunsakin, E. and Iyaniwura, J. 2012. Canonical Correlation Analysis of Poverty and Literacy Levels in Ekiti State, Nigeria, Mathematical Theory \& Modeling, Vol. 2 (6), pp 31-39

[11] Akwara, N., Enwuchola, J., Adekunle, M. and Udaw, J. 2013. Unemployment and Poverty: Implications for National Security and Good Governance in Nigeria, Int. Journal of Pub.Admin \& Mgt Rsch, (IJPAMR), Vol. 2 (1),

[12] Obasola, K. and Omomia, A. 2014. Poverty, Gender and the African Culture and the Challenges of Globalization, Research on Humanities and Social Sciences, Vol. 4 (15), p158-165

[13] Obadan, M.I. and Odusola, A.F. 2001. Productivity and Unemployment in Nigeria. National Centre for Economic Management and Administration, Ibadan.

[14] Debbie, B. and Krisela, S. 2001. Poverty and Chronic Diseases in South Africa, Technical Report 2001 by Burden of Disease Research Unit \& Chronic Diseases of Lifestyle Unit, WHO Collaborating Centre, South Africa

[15] The Institute for Computational Medicine. 2014. Johns Hopkins University, 3400 North Charles Street, Baltimore MD 21218-2686. Accessed in the website on Dec 1, 2014. www.icm.jhu.edu

[16] Institute for Disease Modeling. 2014. Bellevue, WA 98005. Accessed in the website on Dec 1, 2014. http://idmod.org/contact

[17] Center for Disease Modeling. 2014. York University, Canada. Accessed in the website on Dec 1, 2014 http://www.yorku.ca/yihr/?page_id=780

[18] Dembek, Z.F., Kortepeter, M.G. and Pavlin, J.A. (2007) Discernment between deliberate and natural infec. disease outbreaks. Epidem. Infect. Vol 135, p353-371.

[19] Huerta, M. and Leventhal, M. 2002. The epidemiologic pyramid of bioterrorism. Israel Med. Assoc. Journal (IMAJ), Vol. 4, p498-502

[20] Jacques, C. 2004. Bioinformatics-An Introduction for Computer Scientists, ACM Computing Surveys, Vol. 36, No. 2, June 2004, pp. 122-158.

[21] Ikejiaku, B.V. 2009. The Relationship Between Poverty, Conflict and Development, Journal of Sustainable Development, Vol 2 (1), p15-28.

[22] Madan, M.J. 2014. Contours of Impulsive Interactions in Transparency, Economic Stability and Economic Development, The Int. Journal Of Business \& Mgt, Vol 2 (5), p133-141.

[23] Sohel, I. Can E-governance hold back the Relationships between Stakeholders of Corruption? An Empirical 
Study of a Developing Country, Journal of Economics and Business, Vol. 13 (2), 2010, p83-106

[24] Ahmad, A., Naser, A., \& Shebiab, F. 2013. The Impact of Adopting E-Government on Reduce Administrative Corruption: Empirical Evidence from Kuwait's Public Sector, Academy of Contemporary Research Journal, Vol. 2 (2), P31-43.

[25] Pathak, R, Singh, G., Belwal, R., Naz, R. \& Smith,R. 2008. E-governance, Corruption and Public Service Delivery: A Comparative Study of Fiji and Ethiopia, Journal of Admin \& Governance, Vol. 3 (1), p65-79

[26] Ndou, V.D. 2004. E-Government for Developing Countries: Opportunities and Challenges, The Electronic Journal of Information Systems in Developing Countries, Vol. 18 (1), pp. 1-24.

[27] Nicolae, C. 2003. EGOV 2003, LNCS 2739, R. Traumuller (Ed), pp 401-406, Springer-Verlag Berlin Heidelberg.

[28] Directorate of Preventive Services. Corruption Prevention Guidelines on ICT Systems in the Public Sector, Kenya Anti Corruption Commission, Nairobi, March 2008

[29] Abdoulaye,G. 2014. (Ed.), Computing in R\&D in Africa: Benefits, Trends, Challenges \& Solutions, Springer, NY, 2015. ISBN 978-3-3-319-08238-7

[30] EurACC. 2014. The European Anti-Corruption Centre. Accessed Nov 9, 2014 from website. http://euracc.eu/:
[31] Soriano, C.R. 2007. Exploring the ICT and Rural Poverty Reduction Link: Community Telecenters and Rural Livelihoods in Wu'an, China, The Electronic Journal on Information Systems in Developing Countries EJISDC, Vol.32 (1), p1-15

[32] Tarun M., Vineet G, Suneet, S. 2014. Saksham- A Public-private Initiative to Energize the Rural Economy through ICT, Microsoft Press office, India.

[33] Daoliang, Li \& Simon, Y. 2012. 3S and Precision Farming for Agriculture, Intelligent Automation and Soft Computing, Vol. 18, No.8, pp.993-781.

[34] Mitsuyoshi, H., Eiji, K., Tomihiro, Y. 2010. Application of Cloud Computing to Agriculture and Prospects in Other Fields". FUJITSU Sci. Tech. J. Vol. 46, No. 4, pp. 446-454

[35] Float Mobile Company, 2014. mAgriculture: The Application of Mobile Computing to the Business of Farming. Jackson St.Morton, IL 61550 , http://floatlearning.com/contact/ (Website accessed: Nov 10,2014 )

[36] Yanbo, H. and Lacey, R. 2010. Development of soft computing and applications in agricultural and biological engineering. Comp. \& Electronics in Agric., Vol. 7. (2010) pp107-127

[37] World Bank/IMF (2015), Ending Poverty and Sharing Prosperity, International Bank for Reconstruction and Development / The World Bank Report 2015, 1818 H Street NW, Washington DC 